\title{
APPLICATION OF FINITE ELEMENT ANALYSIS IN EFFECTIVE DESIGN OF FLIGHT CONTROL CIRCUITS IN A TYPICAL LIGHT HELICOPTER
}

\author{
Mallikarjun R Killedar ${ }^{1}$, Ramesh Katti ${ }^{2}$, Palli Naresh Babu ${ }^{3}$ \\ ${ }^{1}$ Mtech (Design Engineering), KLE'S Dr. MSSCET, Belgaum \\ ${ }^{2}$ Assistant Professor, KLE'S Dr. MSSCET, Belgaum \\ ${ }^{3}$ Engineer, STRESS Group, RWR\&DC, HAL, Bangalore
}

\begin{abstract}
The objective of this project work is to effectively design and analyze the helicopter flight control circuits. The design process involves FE method to assess the directional control circuit. Displacement, stress, strain energy values are obtained for the circuit for different load cases and optimum design is obtained for safe helicopter flight controls for critical maneuvers.

In a helicopter the rotor blade is operated using mechanical flight control system consisting of elements like push-pull rod, links, bell crank levers, structural supporting brackets etc. There is a certain amount of reduction in stiffness and strength of elements of the circuit due to stretch in these elements resulting in false control surface deflections.

This project work focuses on the application of FEM in design, analysis and optimization of directional flight control circuit using ALTAIR HYPERMESH and MSC NASTRAN software's. FEM techniques have been extensively used in this study to simulate the control circuit mechanism.
\end{abstract}

Keywords: directional control circuit, finite element analysis, displacement, strain energy

\section{INTRODUCTION}

The flight controls modify the pitch angle of the main and tail rotors allowing the pilot to Control helicopter flight by modifying its altitude, speed and heading [2].

In general, the flight control circuits are designed to have minimum stretch in the circuit, not exceeding $20 \%$, as per aircraft standards [1]. Ground tests are carried out to confirm the stretch and stiffness values in the control circuit. Redesign of circuit is carried out, if necessary, to obtain acceptable results. The process is generally iterative in nature, and has both cost and time implications.

Directional/Pedal Control circuit of a typical light helicopter has been chosen for the case study. A detailed FE model is analyzed to predict the stretch and stiffness values more accurately.

\subsection{Directional/Pedal FCS in a Typical Light Helicopter}

In the light helicopter under consideration, the directional control circuit mechanism is fully mechanical, consisting of combination of push pull rods, bell crank levers, supporting Brackets etc. as shown in figure-1.

Series of push pull rods are used between the controls. Bellcrank levers are used at regular intervals to reduce the length of push-pull rods for improving its buckling margins. These are also used to change the direction and leverage of the control circuit.

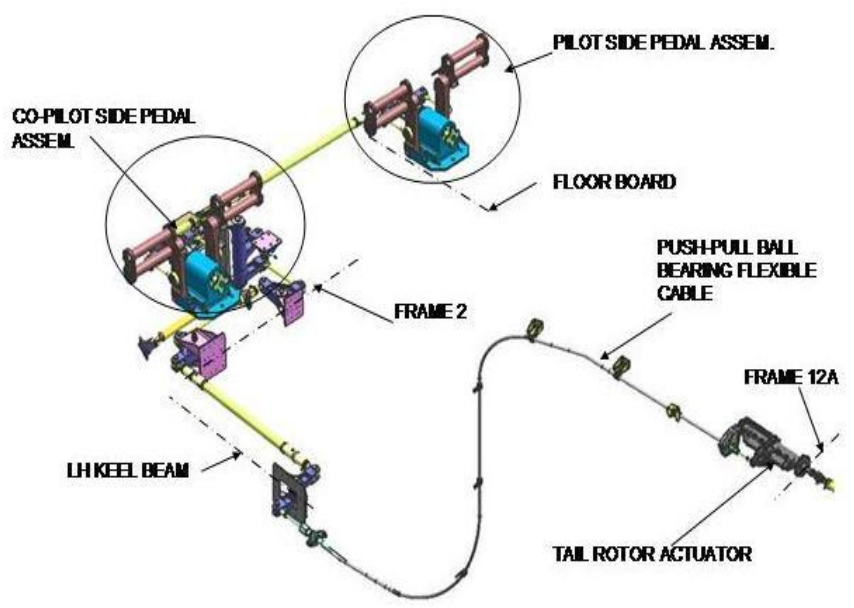

Fig -1: directional/pedal control circuit

\section{FINITE ELEMENT ANALYSES}

FEA software Altair Hyper mesh is used as pre and post processor, and MSC NASTRAN is used as a solver. FE model with appropriate boundary conditions has been used to obtain the optimum lever ratios and load distributions such that the stretch values are within acceptable limit. 
A detailed FE model has been developed using the 1D element (CROD, CBAR) to represent the push-pull rods, bolts, etc. 2D elements (CQUAD4) to represent the frame to which the pedal circuit parts are attached. 3D elements (CTETRA) to represent the bell crank levers, T-levers, offset bell cranks, pedal bracket, fork end, pedal lever, supporting brackets etc.

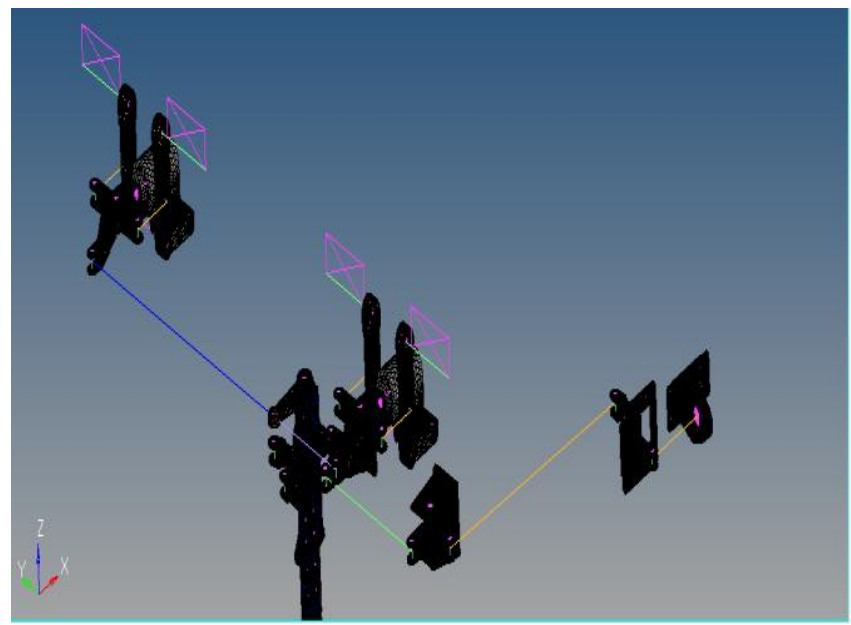

Fig -2: FE model showing directional circuit parts

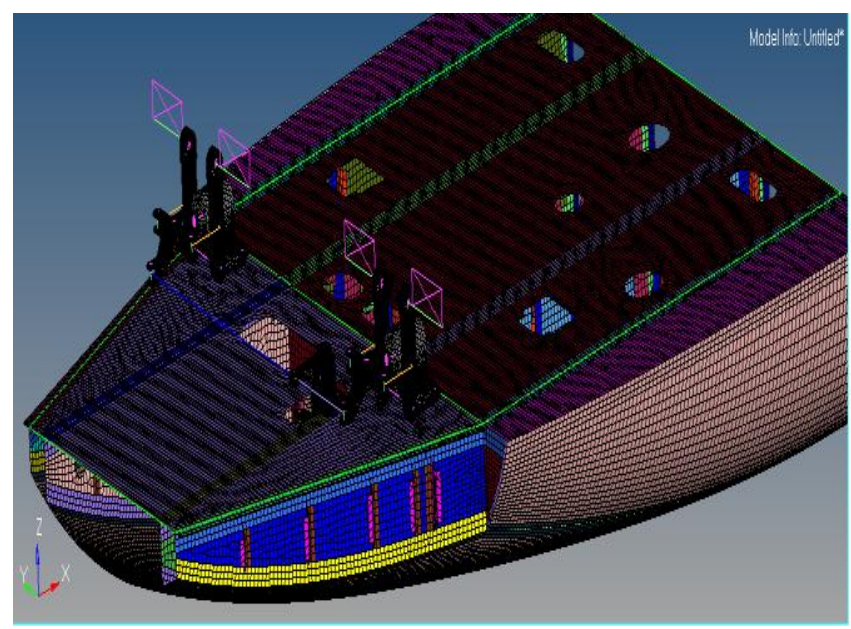

Fig-3: FE model showing parts attached to the lower helicopter frame

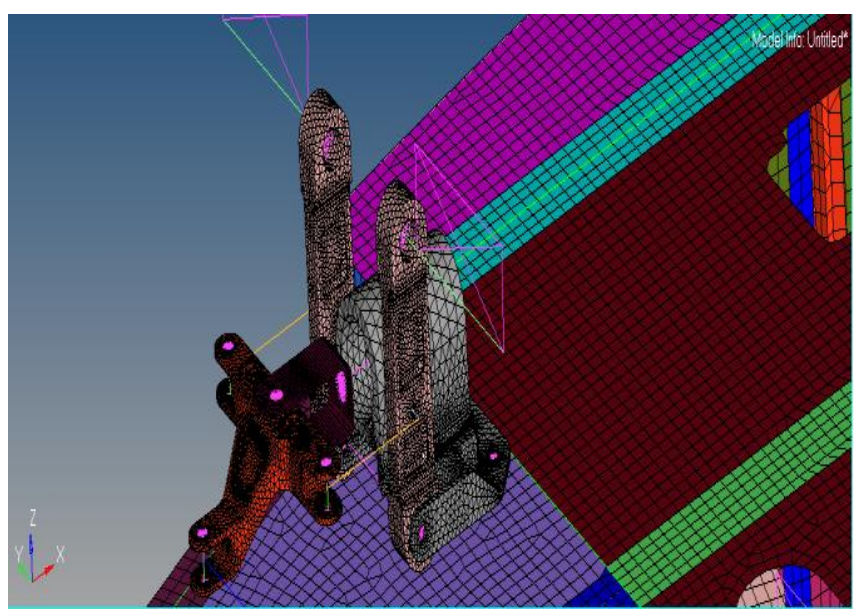

Fig-4 (a) - : components in detail - pedal lever, screw shaft, fork end, T-lever
This FE model consists of all the components in the control circuit along with supporting structure that attaches these FCS components to the lower helicopter structure. Details of the FE model of various components are shown in figure-2, figure- 3 and figure- 4 .

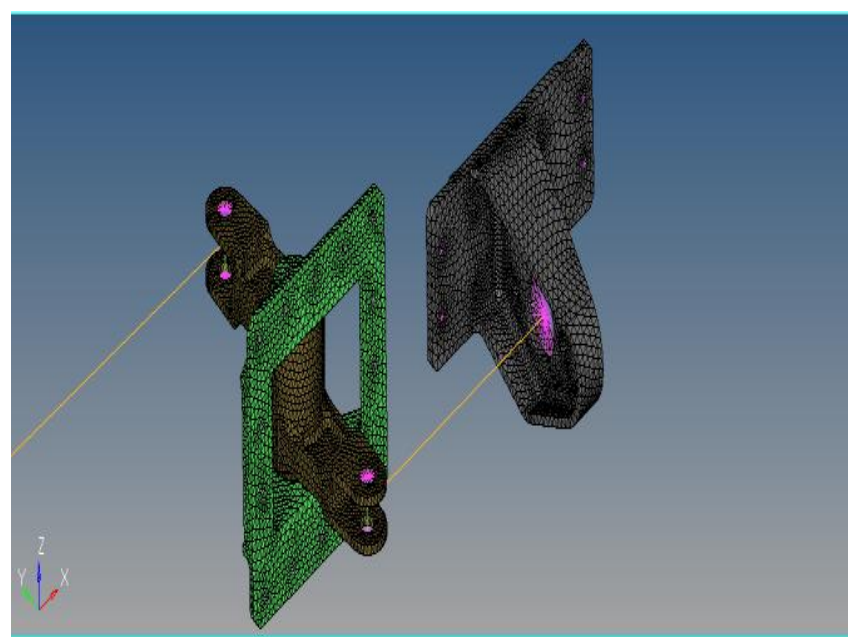

Fig-4 (b): components in detail - supporting brackets, offset lever

Table - 1: mesh details

\begin{tabular}{|l|l|}
\hline Element type & Total number of elements \\
\hline CBEAM & 680 \\
\hline CBAR & 132 \\
\hline CROD & 10 \\
\hline CQUAD4 & 71080 \\
\hline CTETRA & 440526 \\
\hline
\end{tabular}

\subsection{Design Limit Loads}

The Directional control components are designed to withstand the Limit Pilot Loads as specified in FAR 27.397 and 27.399 [5]. Design Limit Load for directional circuit is shown in the table below.

Table - 2: design limit loads

\begin{tabular}{|l|l|ll|}
\hline Channel & $\begin{array}{l}\text { Design limit } \\
\text { loads }\end{array}$ & Direction \\
\hline $\begin{array}{l}\text { Yaw control } \\
\text { (pedal) }\end{array}$ & $589 \mathrm{~N}$ & $\begin{array}{l}\text { Left pedal } \\
\text { forward }\end{array}$ \\
\hline
\end{tabular}

Displacement and strain energy values of the parts and the whole model is obtained.

\section{ANALYSIS AND RESULTS}

Static analysis was carried out for the pilot loads mentioned in FAR [5] using MSC Nastran SOL-101 [4]. The detailed FE model with the optimum leverages obtained by analyzing the parts individually has been analyzed for loads mentioned earlier. The displacements and strain energy plots for the same are shown in Figure-5 and Figure-6. 


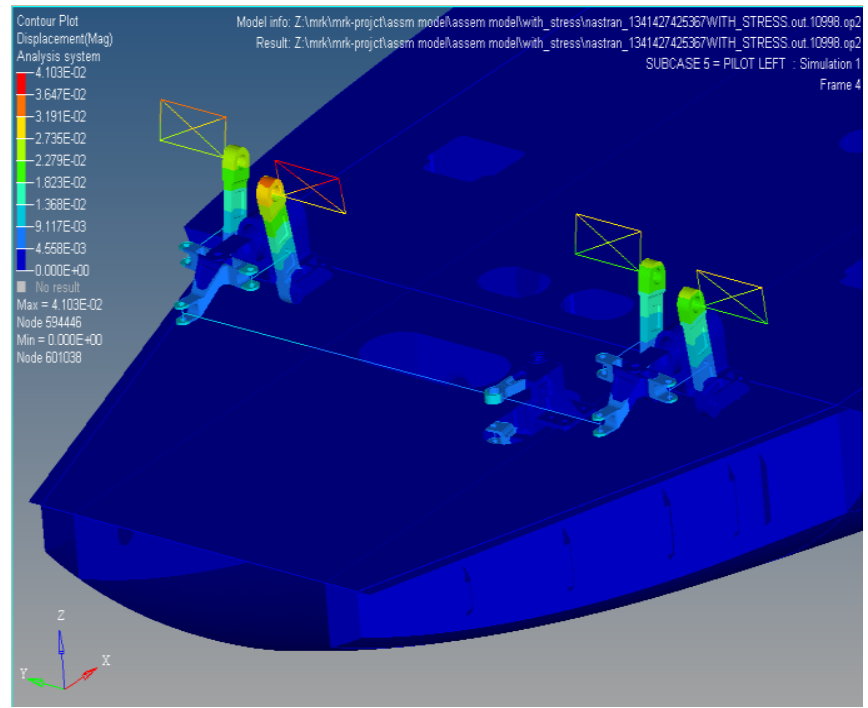

Fig-5 (a): displacement plot for pilot left load case - pedal lever aluminum

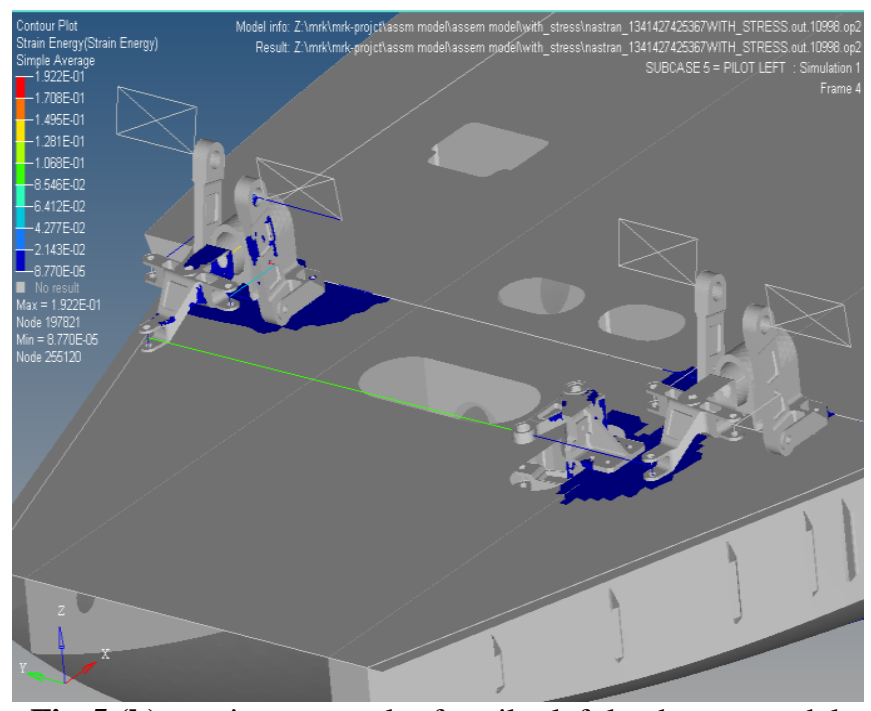

Fig-5 (b): strain energy plot for pilot left load case - pedal lever aluminum

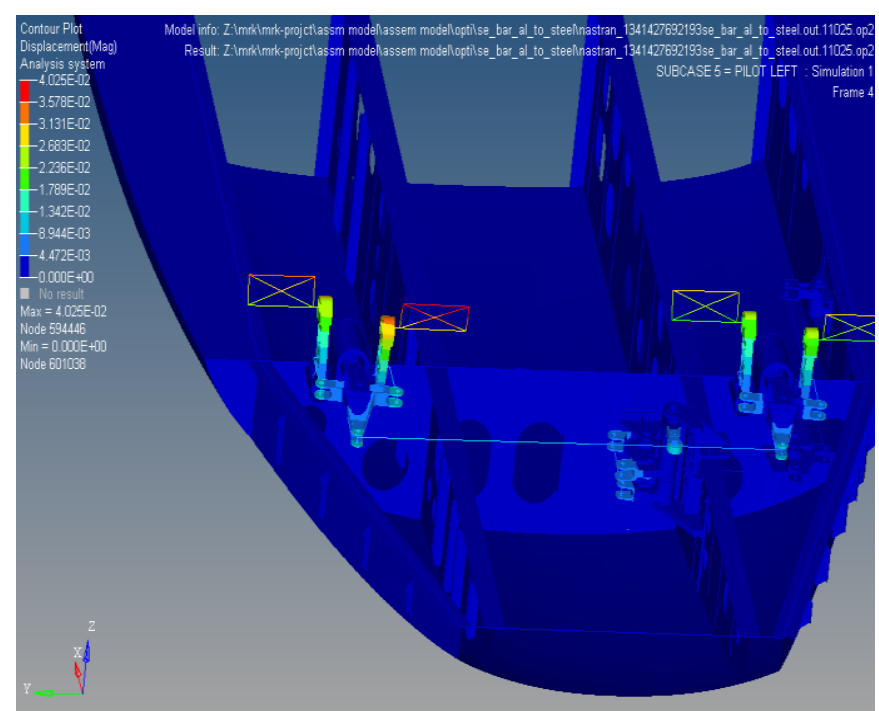

Fig-6 (a): displacement plot for pilot left load case - pedal lever - steel

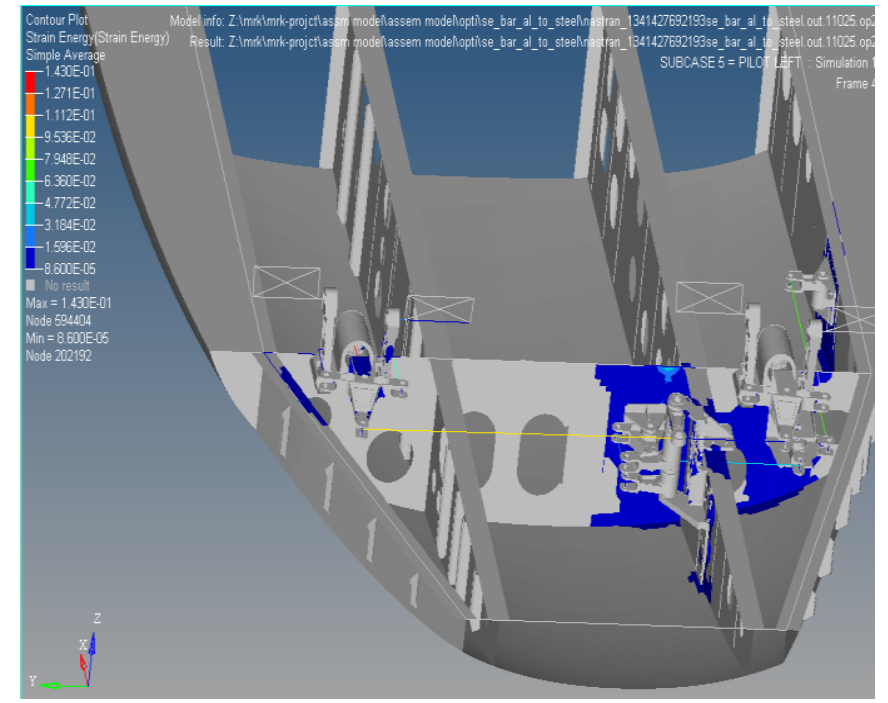

Fig-6 (b): strain energy plot for pilot left load case - pedal lever - steel

As seen in figure 5 displacements are more in the pedal area where the pilot applied the load and initially aluminu $1 \mathrm{~m}$ was used as pedal lever material.

As pedal lever is a critical component since it takes the pilot load, iteration is done using steel as the material and it proves to be optimum as shown in figure 6 giving less displacement and strain energy compared to aluminum.

Steel has more weight than aluminum, so weight wise optimization is not correct, but since it is a critical component it can be used, as there is an option to reduce weight in other components like brackets, levers etc.

The values of displacements and strain energy for the load case for different material of pedal lever are given in the table below.

Table-3: displacement and strain energy values for different pedal lever material

\begin{tabular}{|l|l|l|l|}
\hline Load case & $\begin{array}{l}\text { Pedal lever } \\
\text { material }\end{array}$ & $\begin{array}{l}\text { Displacement } \\
(\mathrm{m})\end{array}$ & $\begin{array}{l}\text { Strain } \\
\text { energy }(\mathrm{N}- \\
\mathrm{m})\end{array}$ \\
\hline $\begin{array}{l}\text { Pilot left } \\
\text { forward }\end{array}$ & aluminum & 0.0041 & 0.192 \\
\hline & steel & 0.0040 & 0.143 \\
\hline
\end{tabular}

\section{CONCLUSION}

The present study demonstrates the application of FEA in design, analysis and optimization of flight control circuits of a typical light helicopter.

A detailed FE model with the optimum leverages has been created and analyzed to predict the displacement and strain energy values more accurately.

It is clear from the figure-5, figure- 6 and table- 3 that values of displacement and strain energy are reduced considerably by replacing pedal lever material from aluminum to steel. 
Since strain energy is reduced impact on the frame by the brackets is reduced, thus less energy is consumed during displacement of the parts, thus giving required travel of all the links.

Using steel as pedal lever material increases weight, but since it is a big control system involving many parts, increase in weight is affordable by considering the strength and stiffness parameters.

\section{REFERENCES}

[1]. http://nal-ir.nal.res.in/12026/2/jeas_0414_1064.pdf

[2]. http://en.wikipedia.org/wiki/Helicopter_flight_controls

[3]. Altair Hyper works 12.0 Documentation, Altair

Engineering Inc.

[4]. MSC Nastran 2012 Documentation, MSC Software Corporation.

[5]. FAA Federal Aviation Regulations (FAR)

\section{BIOGRAPHIES}

Mallikarjun $\mathbf{R}$ Killedar, Presently studying in final semester of MTECH (DESIGN ENGINEERING) in KLE'S Dr. MSSCET, BELGAUM. Completed B.E (MECHANICAL ENGINEERING) from the same college in 2013.

Ramesh Katti, Presently working as an assistant professor in KLE'S Dr. MSSCET, BELGAUM. Completed B.E (MECHANICAL ENGINEERING) and MTECH (DESIGN ENGINEERING) from KLE'S Dr. MSSCET, BELGAUM.

Palli Naresh Babu, Presently working as an engineer in STRESS GROUP, RWR\&DC, HAL, and BANGALORE. Completed BTECH in AERONAUTICAL ENGINEERING from IIT MADRAS. 